Artigo Original

\title{
Por uma educação ambiental crítica no contexto escolar: reflexões a partir das representações dos alunos
}

\author{
For a critical environmental education in the school context: reflections from the students' \\ representations
}

\author{
Salatiel Rocha da Rocha Gomes' \\ José Vicente de Souza Aguiar"
}

\section{Resumo}

A Educação ambiental Crítica no contexto escolar vem ganhando forças a partir de um coletivo de pensamento que sugere a inserção de aspectos sociais, políticos, éticos, estéticos, econômicos e culturais no debate da temática ambiental, ou seja, vai além do aspecto naturalista/biológico/conservador. Nesse sentido, temos como principal objetivo geral verificar que representações alunos de uma turma de $9^{\circ}$ ano possuem sobre meio ambiente, apontando as limitações e as potencialidades de tais representações. Utilizou-se textos, desenhos, aula-passeio e um teste de evocação de palavras como técnica de coleta de dados. Percebeu-se que os alunos relacionam meio ambiente apenas à ideia de natureza, utilizando-se fauna e flora, preservação, lixo, limpeza e cuidado como palavras-chaves dessas representações, ou seja, ainda é presente no contexto escolar a concepção conservadora e preservacionista da educação ambiental.

Palavras-chave: Conservacionista; Crítica; Educação ambiental; Meio ambiente

\section{Abstract}

Critical environmental education in the school context has been gaining strength from a collective of thought that suggests the insertion of social, political, ethical, aesthetic, economic and cultural aspects in the debate on the environmental theme, that is, it goes beyond the naturalistic aspect / biological / conservative. In this sense, we have as main general objective to verify that representations students of a class of 9o year have on environment, pointing out the limitations and the potentialities of such representations. We used texts, drawings, class-walk, and a word recall test as a data collection technique. It was noticed that the students relate environment only to the idea of nature, using fauna and flora, preservation, garbage, cleaning and care as key words of these representations, that is, it is still present in the school context the conservative and preservationist conception of environmental education.

Keywords: Conservationist; Critical; Environmental education; Environment 


\section{Introdução}

Quando começamos a discutir sobre meio ambiente a primeira pergunta que geralmente fazemos é: Afinal, de que meio ambiente estamos falando? De um conceito ou de uma representação social? Reigota (2007) considera o meio ambiente como uma representação social e não um conceito científico. Trata-se de um processo de entendimento que evolui durante o tempo e que depende do grupo que utiliza, o que faz com que, para o autor, o meio ambiente seja "o lugar determinado ou percebido, onde os elementos naturais e sociais estão em relações dinâmicas e em interação" (REIGOTA, 2007, p.14). A definição de Reigota sustentou nossas abordagens durante as reflexões que realizamos nesse estudo, pois entendemos $a$ indissociabilidade entre natureza, ambiente e sociedade.

No Parâmetro Curricular Nacional (PCN) de Meio Ambiente e Saúde, o meio ambiente é definido como "um espaço em que um ser vive e se desenvolve, trocando energia e interagindo com ele, sendo transformado e transformando-o" (BRASIL, 1997). As definições acima mencionam a relação e a interação como palavras-chave para se compreender a expressão meio ambiente. Neste sentido, é interessante dizer que os elementos naturais e sociais estão interligados e indissociáveis. Os elementos naturais citados no PCN do Meio Ambiente e Saúde podem ser retratados da seguinte maneira:

São “como a natureza os fez", sem a intervenção direta do homem: desde cada recurso natural presente num sistema, até conjuntos de plantas e animais nativos, silvestres; paisagens mantidas quase sem nenhuma intervenção humana; nascentes, rios e lagos não atingidos pela ação humana (BRASIL, 1997, p.32).

Neste entendimento, os elementos sociais estão ligados às questões da sociedade, o que constitui um olhar sobre o modo e o estilo de vida das pessoas, o que possibilita uma reflexão sobre questões como as desigualdades sociais. Outra característica corresponde aos espaços já modificados pelo homem, como praças, jardins, plantações, praias urbanizadas, bosques, áreas de lazer, dentre outros, que são ambientes criados para convivência. Estes espaços, são por ora, pouco inseridos como integrantes do meio ambiente, necessitam de ações, principalmente do Estado. Por esta razão, a importância de diálogos visando ações viáveis e proativas e não apenas o pensamento naturalista, inserido contextos como o político. (CARVALHO, 2008).

\section{Educação Ambiental no contexto} escolar

Percebe-se que é natural nas escolas não falar muito das diferentes dimensões da educação ambiental, seja por sua complexidade ou pela própria formação dos professores - Todavia, essas discussões devem ser motivadas pela escola, para que se formem educandos e cidadãos que não reduzam o conceito de meio ambiente a natureza.
Deve-se considerar que, como a realidade funciona de um modo sistêmico em que todos os fatores interagem, o ambiente humano deve ser compreendido em todos os seus inúmeros problemas. Tratar a questão ambiental, portanto, abrange toda a complexidade da ação humana: se quanto às disciplinas do conhecimento ela é um tema transversal, interdisciplinar, nos setores de atuação da esfera pública ela só é consolidada numa atuação do sistema como um todo, sendo afetada e afetando todos os setores: educação, saúde, saneamento, transporte, obras, alimentação, agricultura, etc (BRASIL, 1998, p.44).

O olhar complexo, que analisa o todo não pela junção das partes, mas em sua totalidade e na capacidade de interagir com diferentes elementos (MORIN, 2006) propõe que não se reduza o ato educativo à transmissão de informações das ciências naturais, onde o professor teria a função de, minimamente, difundir as verdades, da maneira como se constituíram, transformando-o em um decodificador e difusor dessas informações prontas e acabadas (CARVALHO, 2008). O contrário seria possibilitar aos educandos momentos de aprendizagem por meio dos quais teriam condições de problematizar e questionar.

Compactuamos com a posição de Leff (2001, p.17) quando relata que "o ambiente não é ecologia, mas a complexidade do mundo; é um saber sobre as formas de apropriação do mundo e da natureza através de relações de poder que se inscreveram nas formas dominantes de conhecimento".

Portanto, qualquer discussão sobre a questão ambiental que prescinda o olhar político iniciará de forma limitada, pois há relações diretas entre as discussões de justiça ambiental e as de natureza política. Essa é a mensagem que essencialmente queremos estabelecer nesse texto. A seguir, conheceremos as concepções sobre meio ambiente, que constam da literatura científica.

Uma das cartografias mais citadas nos estudos sobre meio ambiente é a de Sauvé (2005), em que a autora faz um mapeamento das diferentes concepções sobre o tema. Ela menciona que "meio ambiente é o cadinho em que se forjam nossa identidade, nossas relações com os outros, nosso 'ser-no-mundo' (SAUVÉ, 2005, p. 317). Esse pensamento sugere a inserção do homem como parte integrante da natureza, por isso, a palavra "relação" é tão presente nos discursos mais politizados sobre o assunto. A autora descreve diferentes compreensões sobre o meio ambiente: como natureza, recurso, problema, sistema, como o lugar onde se vive, biosfera e projeto comunitário.

Em relação às práticas de Educação Ambiental realizada nas escolas e nos movimentos sociais percebese que a mais comum é a ideia de meio ambiente como natureza. No entanto, está emergente também os discursos da sustentabilidade, utilizando-se de técnicas de gestão para minimizar o impacto ambiental, que circunscreve o pragmatismo ambiental.

A despolitização do debate ambiental estabelece a possibilidade de busca de soluções tecnocráticas e gerenciais dos problemas, desvinculadas da análise do padrão societário. 
Por isso, é comum falar-se em alternativas exclusivamente tecnológicas para resolver os problemas da poluição, alimentação, conservação dos recursos naturais, como se a gestão de recursos naturais, em uma base científica rigorosa, fosse possível fora de um contexto histórico e sociopolítico determinado (LOUREIRO, 2003, p.12- Grifo nosso).

O trecho destacado cima expressa a ideia pragmática da questão ambiental que vem ganhando muitos adeptos, principalmente por uma boa parte dos empresários. Assim, muitas fábricas acabam se instalando e se sustentando sob a égide desse movimento pragmático, tido como salvacionista.

Outro mapeamento das concepções sobre meio ambiente foi realizado por Marcos Reigota (2006), o qual criou três tipologias. A primeira, denominada de naturalista, relacionada, basicamente, aos aspectos naturais; a segunda, chamada de antropocêntrica, na qual o meio ambiente é caracterizado como recurso para a sobrevivência do ser humano e a terceira, tida como globalizante, integra natureza e sociedade.

Todas essas concepções, tanto a de Sauvé (2005) quanto a de Reigota (1995) consideram as múltiplas formas de entendimento sobre meio ambiente. Deste modo, o consenso que encontramos nos textos dos autores corresponde à necessidade de não olhar para um único caminho, que não se tratam de concepções erradas, mas que se complementam.

Em 2015, a carta Encíclica do Papa Francisco conseguiu mostrar essa multiplicidade e teve uma repercussão mundial bastante aceitável. É claro que não podemos esperar que, a partir dela, mudanças aconteçam. Porém, o legado da carta foi ressaltar que a questão ambiental e o cuidado com a casa comum estão relacionados à crise social. É necessário pensar, segundo o papa, em uma ecologia integral, pois questões como aquecimento global, falta de água, geração de resíduos e outros problemas ambientais, causam danos a todos, porém, mais fortemente aos pobres, que, geralmente, vivem em lugares vulneráveis. Nas palavras do Pontífice (p.107): "Do momento que tudo está intimamente relacionado e que os atuais problemas exigem um olhar que atenda a todos os aspectos da crise mundial, proponho uma ecologia integral que compreenda claramente as dimensões humanas e sociais”.

A carta Encíclica também menciona, de forma analítica e crítica, problemas como os padrões dominantes de produção e consumo; tece considerações sobre o antropocentrismo e sugere uma nova postura frente às injustiças sociais. Relata repetidamente que a questão ambiental está interligada à questão social. "Toda análise dos problemas ambientais é inseparável da análise dos contextos humanos, familiares, trabalhistas, urbanos e da relação de cada pessoa consigo mesma, que cria um determinado modo de relações com os outros e com o ambiente” (p.109).

Pensar nessas diferentes compreensões sobre o meio ambiente é mais consensual do que divergente, no entanto, é necessário relacioná-las à prática de Educação Ambiental nas escolas e nos movimentos sociais. Para Reigota (2007), as concepções que as pessoas possuem sobre meio ambiente, balizarão as práticas e os entendimentos sobre a
Educação Ambiental. Cabe aqui, a seguinte interrogação: Quais, necessariamente, são as intenções desta Educação Ambiental posta no contexto atual da sociedade?

\section{Caminho Metodológico}

A pesquisa foi realizada em uma turma de 9응 ano, de uma escola Municipal da Cidade de Manaus. Participaram 28 alunos, da idade de 15 a 17 anos, os quais foram autorizados, via termo de livre consentimento e esclarecimento, por seus responsáveis.

Iniciamos nossa atividade de campo apresentando a proposta de pesquisa aos alunos, deixando clara a intenção do estudo. Os alunos ficaram entusiasmados com a proposta e mencionaram que estavam dispostos a adquirirem novos conhecimentos. Mencionamos que tratava-se de uma pesquisa que aconteceria na escola, em seu entorno e nos espaços não-formais. Comentaram que era necessário conhecer mais sobre o meio ambiente porque havia muitos alunos que sujavam e não jogavam o lixo no lixo, nem faziam "direitinho" a coleta seletiva.

Solicitamos um nome para o grupo. Determinamos 30 minutos para a escolha do nome, dentre as seguintes sugestões: SOS Natureza, SOS Meio Ambiente; LNL (Lixo no Lixo), Grupo Verde e LEV (Limpeza é Vida) que foi o mais votado e, portanto, o nome escolhido para o grupo. Pelo nome, já imaginávamos qual seria a maior representação que os alunos teriam sobre meio ambiente.

Surgiu a ideia de criar um grupo no aplicativo WhatsApp para discutirmos algumas temáticas. Uma aluna, que se prontificou a ser secretária do grupo, e a seguir adicionou os participantes e uma imagem, conforme figura $1 . \mathrm{Na}$ primeira semana, não postaram nenhum comentário sobre

Figura 1: Imagem colocada pelos alunos na capa do Grupo no WhatsApp

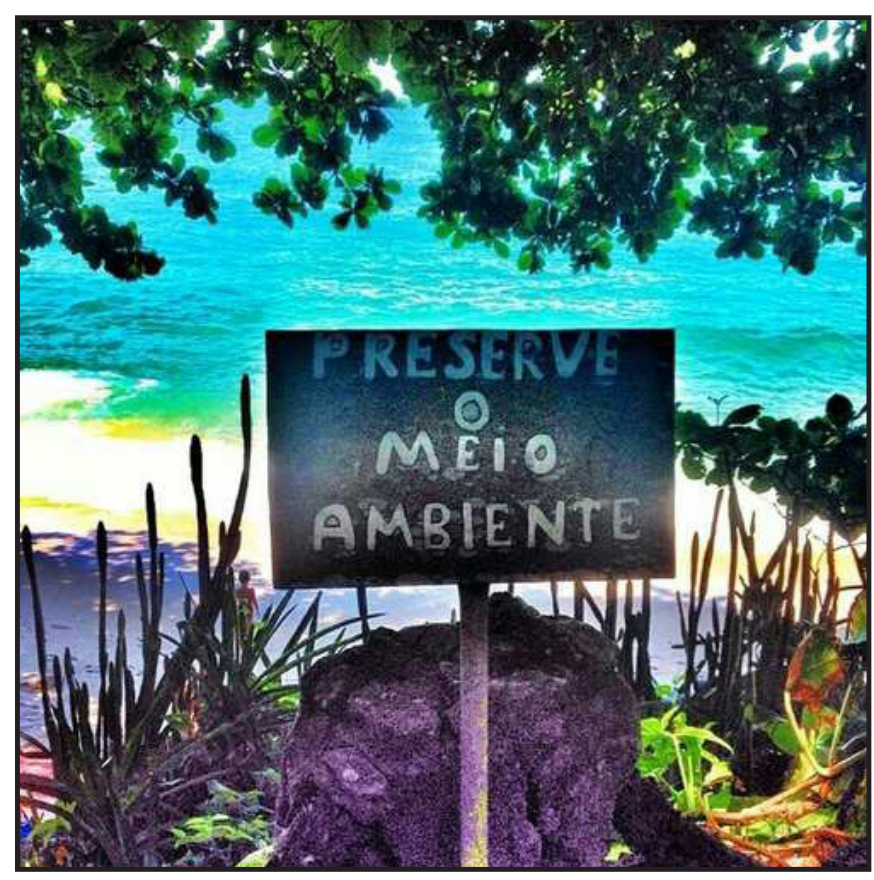

Fonte: Dados da pesquisa 
o foco do estudo. As postagens eram voltadas às relações de amizade e das disciplinas do colégio, em uma linguagem típica dos adolescentes. Porém, os deixamos livres para que pudessem tecer comentários de forma espontânea. Dos 29 alunos, 20 possuíam o aplicativo e participavam de algumas discussões que faríamos posteriormente.

A partir do contrato didático inicial, realizamos três momentos para verificarmos as representações iniciais dos estudantes sobre o meio ambiente. Utilizamos as atividades de textos, desenhos e aula-passeio. Para realização dessas atividades, nos sustentamos nos textos de Giordan e Vecchi (1996, p.104), quando relatam que "a utilização de uma só ferramenta didática é muito artificial e, em todo o caso, por demais pobre para dar conta de uma concepção precisa”.

\section{As representações através de textos}

A primeira atividade realizada foi a de produção de textos, através de um questionário com uma única questão․ Dizia: Descreva o que você compreende sobre o tema Meio Ambiente. Teve-se o cuidado de não induzirmos as respostas como nos adverte Becker (1997). As respostas foram categorizadas, conforme a proposta de Bardin (1977), descobrindo, os núcleos de sentido e à luz dos estudos sobre meio ambiente de Sauvé (2005) ${ }^{\mathrm{II}}$.

De acordo com o quadro 1 , constatamos que $84 \%$ das respostas se relacionam com a ideia de meio ambiente como natureza, característica de uma educação ambiental conservacionista como aponta Guimarães (2004).
Destacamos o seguinte bloco de falas:

Meio Ambiente como natureza

(E2) - Para mim, o meio ambiente significa cuidar da natureza, porque não é legal passear e ver a floresta cheia de latas, sacolas e garrafas.

(E6) - O meio ambiente é um bem natural que Deus nos deixou para preservamos e cuidarmos. Nele, apreciamos belas paisagens, como rios, árvores. Estas, porém, infelizmente, estão sendo destruídas pelo homem. Outra coisa que me entristece muito no meio ambiente é o desmatamento. Temos uma floresta tão bonita, tão imensa, mas o homem também está destruindo. Devemos cuidar do meio ambiente como cuidamos de nossa casa, pois em nossa casa não jogamos lixo, não destruímos as coisas. Assim, devemos cuidar daquilo que Deus nos deixou.

(E7) - Para mim, o meio ambiente, ou seja, a natureza, é muito importante e se todos fizerem sua parte conseguiremos tanto viver em paz com a natureza quanto com nós mesmos.

\section{Meio Ambiente é tudo}

(E3) - O meio ambiente é tudo o que há de melhor, portanto, não devemos jogar lixo nas ruas, e sim em suas lixeiras, as árvores, as plantas, jardins localizados em florestas fazem parte da natureza e até mesmo nós fazemos parte dela. Tudo isso constitui o meio ambiente.

Quadro 1 - Representações dos alunos sobre meio ambiente nos textos.

\begin{tabular}{|c|c|c|c|}
\hline Categorias & $\begin{array}{l}\text { Qtde. de } \\
\text { respostas }\end{array}$ & $(\%)$ & Definição de Categoria \\
\hline $\begin{array}{l}\text { Relação do meio ambiente somente } \\
\text { com a natureza. }\end{array}$ & 25 & 84 & $\begin{array}{l}\text { O meio ambiente é relacionado apenas à natureza, } \\
\text { como a fauna e flora, rios etc. }\end{array}$ \\
\hline $\begin{array}{l}\text { Relação do meio ambiente com a } \\
\text { sociedade }\end{array}$ & 0 & 0 & $\begin{array}{l}\text { Percepção que meio ambiente envolve as } \\
\text { dimensões social, econômica, política, ética e que } \\
\text { há indissociabilidade entre natureza e sociedade. } \\
\text { Inclui o homem como integrante do ambiente. }\end{array}$ \\
\hline Definição que meio ambiente é tudo. & 2 & 6 & Visão generalizada de que meio ambiente é tudo. \\
\hline $\begin{array}{l}\text { Meio Ambiente como lugar para se } \\
\text { viver. }\end{array}$ & 0 & 0 & $\begin{array}{l}\text { O lugar onde vivemos, moramos, como o bairro, } \\
\text { nossa casa, cidade e comunidade. }\end{array}$ \\
\hline Meio Ambiente como recurso. & 3 & 10 & $\begin{array}{l}\text { Preocupação com os recursos naturais, sendo } \\
\text { necessária a gestão dos recursos. }\end{array}$ \\
\hline Não elucidado. & 0 & 0 & $\begin{array}{l}\text { Não se evidencia qual a compreensão sobre meio } \\
\qquad \text { ambiente. }\end{array}$ \\
\hline TOTAL & 30 & 100 & \\
\hline
\end{tabular}

Fonte: Elaboração dos autores

'Trazemos o pensamento de Giordan e Vecchi (1996, p.108), quando mencionam que "as perguntas abertas permitem ao pesquisador não revelar suas motivações ou suas próprias representações".
" Sabemos que as respostas podem estar relacionadas a vários tipos de concepção, todavia, analisamos a ideia central, categorizando-a na concepção predominante. 
(E4) - Meio ambiente envolve tudo o que faz parte de nossas vidas, meio ambiente é respeito, ajuda, compreensão, persistência, carinho e amor e várias outras coisas. Devemos cuidar do ambiente onde vivemos, isso inclui não jogar lixo nos rios e nos lagos e nem na rua, não desmatar nossa floresta, aprender a reutilizar as coisas que são possíveis, enfim, devemos cuidar do que é nosso, cuidar do nosso planeta, por isso, o dever de preservar;

\section{Meio Ambiente como recurso}

(E1) - O que aprendi sobre meio ambiente é que temos que economizar água na hora de tomar banho, na hora de escovar os dentes, na hora de lavar a louça, na hora de lavar o carro e a moto, porque a nossa água um dia pode acabar, como em São Paulo. Eles também tinham água com abundância como nós temos. Então, para que isso não venha acontecer conosco, vamos economizar água.

(E5) - O que eu posso falar de meio ambiente é que nos dias de hoje a poluição está mais avançada do que antigamente como os rios. Antes a água era pura e dava pra beber e, agora, nós só vemos lixo, não dá para beber e nem para tomar banho; os esgotos são entupidos de lixo, pois as pessoas jogam na rua e o lixo acumula e vai entupindo esgoto e poluindo, além de causar mau odor e atrair doenças e ratos. O que nós podemos fazer para ajudar o meio ambiente é na hora da coleta de nossos lixos temos que separar eles. Se tem garrafa plástica, faça algum artesanato para reciclar o plástico. Vamos parar de jogar lixo na rua. Em vez de andar de ônibus, vamos caminhar ou andar de bicicleta.

A fala do E1 menciona um grande problema que temos na maioria das práticas de educação ambiental nas escolas: o de citar apenas a preservação e a conservação dos recursos, conforme já mencionava os estudos de Reigota (2007) e Guimarães (2004). Estas práticas influenciam diretamente nas representações dos alunos, sendo o posicionamento comportamentalista, o mais citado pelos alunos. O relato do E5, é uma reprodução de um discurso usualmente utilizado com efeito de verdade, no qual somente algumas ações, como separar o lixo corretamente, andar de bicicleta e reciclar ajudam no combate à destruição do meio ambiente.

De modo geral, as falas dos educando apresentaram esses elementos, são respostas convencionais, provenientes de um discurso centrado no indivíduo, apenas. Seguiremos ainda, avaliando as representações, só que, agora, através de desenhos.

\subsection{As representações através de desenhos}

A segunda atividade realizada foi a produção de desenhos. Foram feitos desenhos livres, sem quaisquer intervenções dos pesquisadores. Continuamente perguntavam se podiam desenhar "isso ou aquilo" e percebíamos a preocupação dos alunos em demonstrar aquilo que era belo. Uns diziam que não sabiam desenhar, por isso seus desenhos sairiam "feios". Entretando, não era esse o nosso objetivo, queríamos compreender as suas representações. Mesmo nas conversas espontâneas que tínhamos com eles ao realizarem os desenhos, já observamos a concepção predominante de ambiente como natureza. As árvores, a fauna e a flora, o sol e o rio foram as imagens mais presentes em seus desenhos.

Frases como "Jogue o lixo na lixeira", "Preserve a natureza" e "A natureza é linda” ganharam destaque nos desenhos. Essa questão foi bastante comentada pelos alunos no momento em que desenhavam e estão analisadas conforme quadro 2 .

O que constatamos no quadro 2 é que a concepção predominante foi a do meio ambiente como natureza. Acreditamos que esta abordagem não politizada é fruto

Quadro 2 - Representações dos alunos sobre meio ambiente nos desenhos

\begin{tabular}{|c|c|c|c|}
\hline Categorias & $\begin{array}{l}\text { Qtde de } \\
\text { respostas }\end{array}$ & (\%) & Definição de Categoria \\
\hline $\begin{array}{l}\text { Relação do meio ambiente somente } \\
\text { com a natureza. }\end{array}$ & 19 & 76 & $\begin{array}{l}\text { Desenhos que contêm apenas elementos da } \\
\text { natureza: fauna, flora, água, rios, sol, nuvens etc. }\end{array}$ \\
\hline $\begin{array}{l}\text { Relação do meio ambiente com a } \\
\text { sociedade e a natureza. }\end{array}$ & - & - & $\begin{array}{c}\text { Desenhos que revelam aspectos da sociedade, } \\
\text { relacionados às questões sociais, econômicas e } \\
\text { políticas etc. }\end{array}$ \\
\hline Meio ambiente como problema. & 5 & 20 & $\begin{array}{l}\text { Desenhos que expressam problemas ambientais: } \\
\text { lixo, poluição etc. }\end{array}$ \\
\hline Meio ambiente como recurso. & 1 & 4 & $\begin{array}{c}\text { Desenhos que propõem alternativas para } \\
\text { problemas ambientais, como coleta seletiva, } \\
\text { reciclagem etc. }\end{array}$ \\
\hline Não elucidado. & - & - & $\begin{array}{l}\text { Não se evidencia qual a compreensão sobre o meio } \\
\qquad \text { ambiente. }\end{array}$ \\
\hline TOTAL & 25 & 100 & \\
\hline
\end{tabular}


de um discurso produzido, histórico e emergente de uma escola de formação que orientou, durante muito tempo, a compreensão sobre meio ambiente e, consequentemente, a Educação Ambiental. Por isso, quase sempre, verificamos a repetição de alguns elementos, tais como, árvores sempre verdes e cheias de frutos e flores, o sol ora sorrindo ora chorando, as nuvens e pássaros sempre em grupo. Como Orlandi (2007) expõe:

Alguma coisa mais forte - que vem pela história, que não pede licença, que vem pela memória, pelas filiações de sentidos constituídos em outros dizeres, em muitas outras vozes, no jogo da língua que vai-se historicizando aqui e ali, indiferentemente, mas marcada pela ideologia e pelas posições relativas ao poder - traz em sua materialidade os efeitos que atingem esses sujeitos apesar de suas vontades. O dizer não é propriedade particular. As palavras não são só nossas (ORLANDI, 2007, p.32).

Em geral, as imagens revelam uma natureza que é bela, organizada, colorida, quase sempre limpa, mesmo com a grande quantidade de mensagens quanto ao lixo. Este tipo de natureza é idealizada pelos alunos como a que sempre está em perfeita harmonia com os homens. Nas figuras 2 e 3 , são exibidas duas ilustrações confeccionadas em sala de aula.

Figura 2 - Desenho representando meio ambiente como natureza - Estudante 1

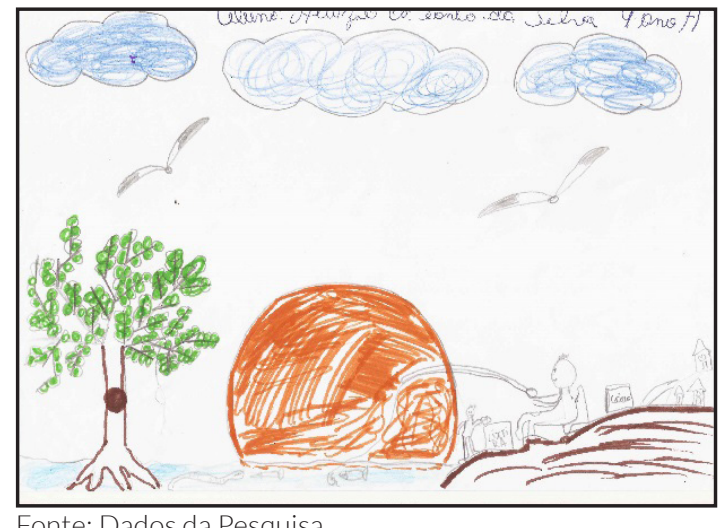

Figura 3 - Desenho representando meio ambiente como natureza - Estudante 2

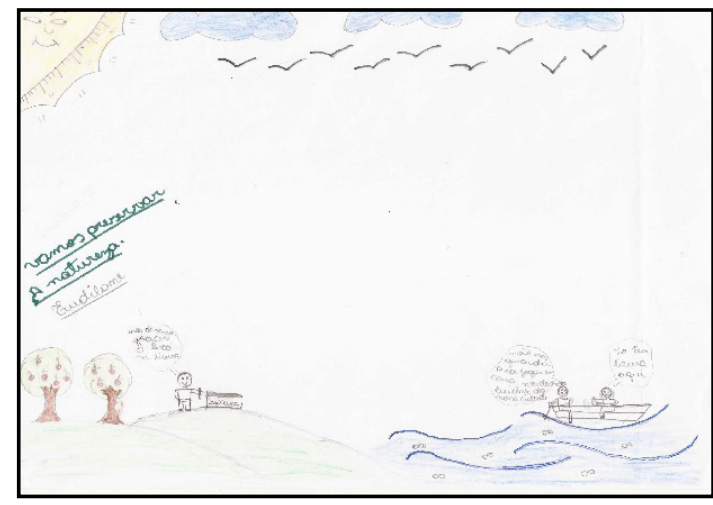

Fonte: Dados da Pesquisa
Uma interessante característica presente nos desenhos acima são as imagens das árvores e animais. Apesar dos discursos de que boa parte da fauna e flora estão em constante degradação, como é o caso do desmatamento ilegal, elas aparecem sempre bem conservadas, com folhas, flores e muito verde. Os animais possuem a mesma forma e estão sempre voando, o que caracteriza a harmonia entre homem e natureza.

Outros desenhos expressaram o meio ambiente como recurso, destacando a necessidade de atividades como reciclagem e coleta seletiva, conforme expressa o desenho da figura 4:

Figura 4: Desenho representando meio ambiente como recurso - Estudante 3

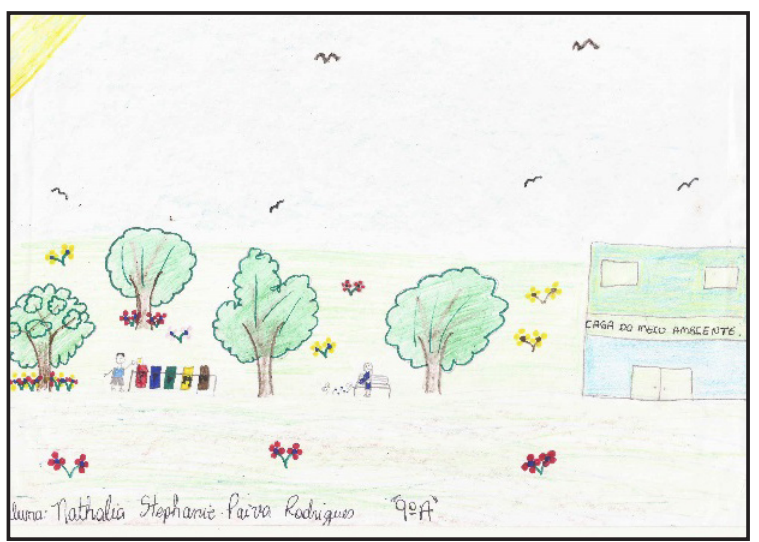

Fonte: Dados da Pesquisa

Mesmo apresentando elementos da fauna e flora, o desenho da figura 4 destaca-se pela inserção de depósitos de coleta seletiva e construção de uma casa do meio ambiente. Possivelmente, o aluno entende a necessidade de se ter uma gestão dos recursos.

$\mathrm{Na}$ figura 5, o desenho expressa o meio ambiente como problema.

Figura 5 - Desenho representando o meio ambiente Estudante 4

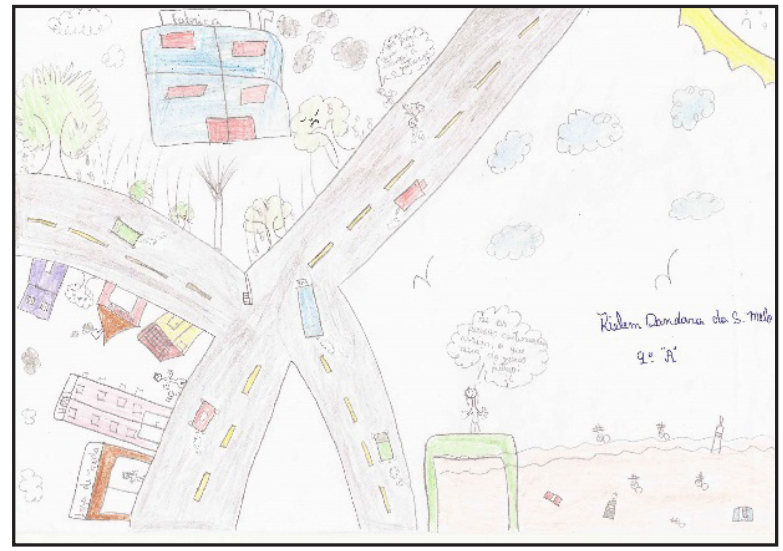

Fonte: Dados da Pesquisa

O desenho mostra possíveis interpretações relacionadas à vida urbana, caracterizada, principalmente, pela presença de prédios e automóveis. O educando 
também fez menção ao problema ambiental: o lixo. Nos desenhos apresentados, tem-se o meio ambiente relacionado somente à natureza como a maior representação social dos alunos, confirmando a mesma ideia obtida nos textos.

\subsection{As representações através de uma aula- passeio no bairro}

A última atividade conduzida foi a aula-passeio no bairro, conforme figuras 6 e 7. Os alunos, autorizados pelos responsáveis, sentiram-se entusiasmados ao realizar a visita nas ruas do bairro, seja por saírem com seus pares ou mesmo pelo objetivo da visita. Explicamos o objetivo da visita e pedimos que anotassem o que eles percebiam sobre o meio ambiente. Neste momento, não era nossa intenção que expressássemos nossas impressões, mas que, de maneira livre, eles apontassem questões sobre o meio ambiente. Primeiramente, visualizaram apenas problemas relacionados ao lixo. $\mathrm{Na}$ sequência, admiraram-se das placas ou indicações. Tudo se voltava ao lixo. A admiração pelas placas mencionando "Jogar lixo na lixeira”, ou então, da quantidade de lixo no chão, nos levava a, previamente, perceber que as suas representações se voltavam à questão da limpeza, mesmo quando ao comprarem "dindin III", jogavam a embalagem no chão.

Ao passarmos pela serraria uma aluna teve a curiosidade de perguntar a um morador se o carro do lixo passava todos

Figura 6 - Estudantes caminhando no bairro

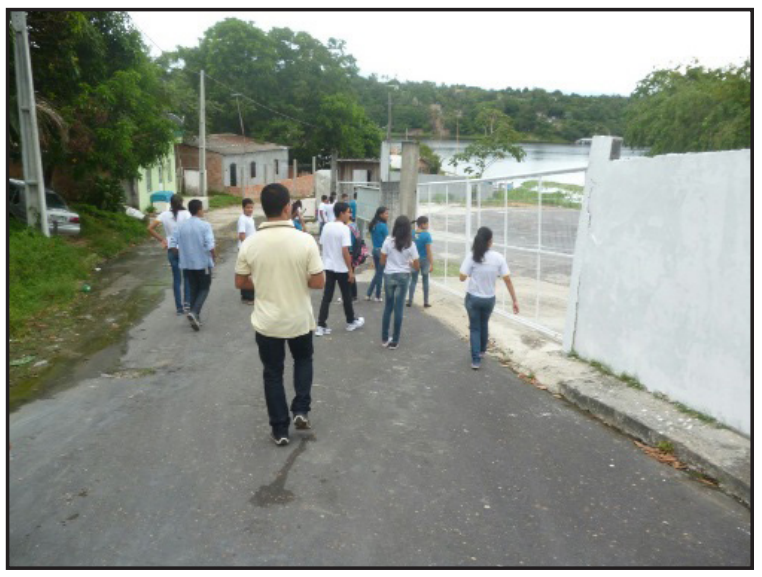

Fonte: Dados da Pesquisa

os dias. O morador falou que não, que esse é um problema do bairro e que ninguém resolve. Segundo o mesmo, o caminhão do lixo passa apenas duas vezes na semana, fato que faz com que o lixo se acumule nas calçadas das casas.

A mesma aluna, com a devida permissão, entrou em contato com a unidade da secretaria municipal de limpeza pública, e questionou a respeito da coleta de lixo. A secretaria informou que a coleta ocorre diariamente, o

\footnotetext{
"ITrata-se de um suco congelado vendido em saco plástico.

${ }^{\prime}$ Apesar do censo de 2010, apontado pelo IBGE, não apresentar no bairro, moradias em condições subnormais, é possível presenciar várias casas em depressões de terra, praticamente firmadas em barrancos. Outras, são
}

qual não corresponde a informação obtida anteriormente por um membro da comunidade.

Outro ponto de parada foi o entorno do cemitério do bairro e, ao chegarmos, visualizamos vários meninos soltando pipa dentro do local. Segundo os alunos, é um hábito, até porque o cemitério fica próximo às casas e não há muros nas laterais. Comenta-se que já houve casos de encontrarem crianças brincando com o crânio de pessoas. Como um cemitério pode ser praticamente uma rua do bairro, onde as pessoas circulam livremente e crianças brincam como se estivessem nos quintais de suas casas?

Figura 6 - Estudantes caminhando no bairro

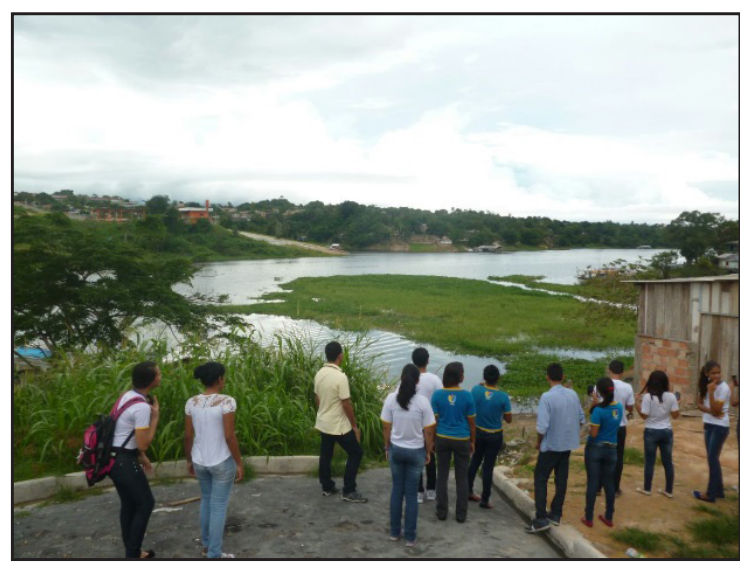

Fonte: GOMES, Salatiel da R; AGUIAR, J.V, 2015

O próximo ponto de parada foi em um barracão. De início, não estava em nosso plano visitar, mas um aluno nos perguntou se poderíamos parar ali, pois queria nos mostrar algo relacionado ao meio ambiente. Dissemos que sim e todos caminhamos até o local. O interessante foi perceber que alguns deles ainda não conheciam o local, mesmo sendo moradores daquele bairro. O lugar é totalmente caracterizado por situações precárias de moradia ${ }^{\mathrm{IV}}$ e de pessoas residindo em extremo perigo, principalmente de desabamento. No entanto, fomos levados pelos alunos a alguns pequenos lixões, que os impressionaram. Concluíram que as pessoas não zelam pelo lugar onde moravam.

Durante o retorno à escola, ouvimos seus comentários e impressões sobre o passeio, e mencionaram o quanto tinha sido "legal" essa visita e que queriam conhecer outros lugares do bairro e, assim, terminamos nossa aula-passeio ouvindo, dentro do ônibus, os alunos cantarem músicas que não conhecíamos, mas que retratavam seus gostos musicais.

No encontro seguinte, solicitamos aos alunos que fizessem um mapa livre, descrevendo algumas palavras que representariam o que encontraram ou mesmo definiam o bairro em que moravam e a sua relação com o meio ambiente. Não definimos quantidade de palavras e os deixamos à vontade para que escrevessem. O quadro 3 traz as palavras evocadas pelos educandos. 
Quadro 3 - Palavras evocadas pelos alunos nas representações iniciais

\begin{tabular}{|c|c|c|c|}
\hline Palavras & Quantidade & Palavras & Quantidade \\
\hline Cuidado & 24 & Harmonia & 4 \\
\hline Natureza & 24 & Consciência & 4 \\
\hline Preservação & 18 & Responsabilidade & 3 \\
\hline Fauna e Flora & 16 & Casas & 3 \\
\hline Limpeza & 9 & Reciclagem & 3 \\
\hline Florestas & 9 & Cidades & 2 \\
\hline Lixo & 9 & Saúde & 2 \\
\hline Pessoas & 8 & Riquezas & 2 \\
\hline Poluiçãa & 8 & Lar & 2 \\
\hline Rios e lagos & 8 & Deus & 2 \\
\hline Amor & 8 & Paisagem & 2 \\
\hline Animais & 7 & Ecossistema & 1 \\
\hline Biodiversidade & 7 & Praças & 1 \\
\hline Planeta & 7 & Justiça & 1 \\
\hline Água & 7 & Cidadania & 1 \\
\hline $\operatorname{Ar}$ & 6 & Contaminação & 1 \\
\hline Respeito & 5 & Comunidade & 1 \\
\hline Lugar & 5 & Amizade & 1 \\
\hline Lazer & 5 & Queimada & 1 \\
\hline Desmatamento & 4 & Família & 1 \\
\hline
\end{tabular}

Fonte: Elaboração dos autores

\section{Considerações Finais}

A pesquisa realizada a partir das representações dos alunos mostrou algumas fragilidades existentes no contexto escolar a respeito da educação ambiental, limitada apenas a uma vertente. Uma possível justificativa para esse cenário podemos encontrar no processo de formação dos professores e nos modos de subjetivação presentes principalmente nos meios e redes sociais, os quais, maciçamente apontam apenas para o aspecto biológico.

Como mencionamos, torna-se um problema quando a escola se sustenta por uma única concepção, por isso, é importante investir, dentro do contexto escolar, em diálogos interdisciplinares que percebam o homem integrado à sociedade e que insiram os aspectos da educação ambiental crítica, dando luz e sentido aos diferentes aspectos que envolvem o meio em que vivemos.

\section{Referências}

AFONSO, Tatyana de Melo. Educação Ambiental no Ensino de Ciências: formação, prática e transversalidade (dissertação de mestrado). Manaus: UEA, 2011.
BARDIN, L. Análise de conteúdo. Portugal: Lisboa, 1977.

BECKER, Howard S. Métodos de Pesquisa em Ciências Sociais. São Paulo: Editora Hucitec, 1997.

BRASIL. Secretaria de Educação Fundamental. Parâmetros Curriculares Nacionais dos anos iniciais: meio ambiente e saúde. Brasília, 1997.

BRASIL. Secretaria de Educação Fundamental. Parâmetros Curriculares Nacionais dos anos finais: meio ambiente e saúde. Brasília, MEC, 1998.

CARVALHO, Izabel Cristina de Moura. Educação Ambiental: a formação do sujeito ecológico. São Paulo: Cortez, 2008.

Carta Encíclica Laudato Si' do Santo Padre Francisco sobre o Cuidado da Casa Comum, Vaticano, 18/06/2015. Disponível em: http://w2.vatican.va/content/francesco/ pt/encyclicals/documents/papa-francesco_20150524_ enciclica-laudato-si.pdf. Acesso em 28.06.2015.

GIORDAN, A.; VECCHI, G. de. As origens do saber: das concepções dos aprendentes aos conceitos científicos. 2 Ed. Porto Alegre: Artes Médicas, 1996. 
GUimarÃES, Mauro. A formação de educadores ambientais. Campinas, SP: Papirus, 2004.

LEFF, Enrique. Epistemologia ambiental. São Paulo: Cortez, 2001.

LOUREIRO, Carlos Frederico B. O movimento ambientalista e o pensamento crítico: uma abordagem política. Rio de janeiro: Quartet, 2003.

MORIN, Edgar. Introdução ao pensamento complexo. Porto Alegre: Sulina; 2006.

ORLANDI, E. P. Análise de Discurso - Princípios e

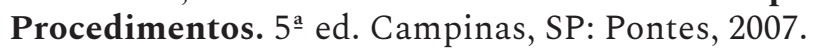

REIGOTA, Marcos. Meio ambiente e representação social. São Paulo: Cortez, 1995.

REIGOTA, Marcos. O que é educação ambiental. São Paulo: Brasiliense, 2006.

Reigota, Marcos. O Estado da Arte da Pesquisa em Educação Ambiental no Brasil. Pesquisa em Educação Ambiental, vol. 2, n. 1 - pp. 33-66, 2007. 